\title{
Análise espaço-temporal de Área de Proteção Permanente para a gestão ambiental municipal em Parauapebas no estado do Pará-Brasil
}

\author{
Spatio-temporal analysis of the Permanent Protection Area for municipal environmental \\ management in Parauapebas in the state of Pará-Brazil \\ Análisis espacio-temporal del Área de Protección Permanente para la gestión ambiental municipal \\ en Parauapebas en el estado de Pará-Brasil
}

Recebido: 26/04/2021 | Revisado: 04/05/2021 | Aceito: 12/05/2021 | Publicado: 29/05/2021

Charles Benedito Gemaque Souza

ORCID: https://orcid.org/0000-0002-5966-9556 Secretaria de Estado de Meio Ambiente e Sustentabilidade, Brasil E-mail: gemaquec@ufpa.br

Francimary da Silva Carneiro

ORCID: https://orcid.org/0000-0002-1693-8779

Secretaria de Estado de Meio Ambiente e Sustentabilidade, Brasil

E-mail: francimarycarneiro@gmail.com

Hellem Cristina Teixeira Rodrigues

ORCID: https://orcid.org/0000-0003-2671-8742

Secretaria de Estado de Meio Ambiente e Sustentabilidade, Brasil

E-mail: hellem.cristinat@gmail.com

Ellen Gabriele Pinto Ribeiro

ORCID: https://orcid.org/0000-0002-1693-8779

Secretaria de Estado de Meio Ambiente e Sustentabilidade, Brasil E-mail: ellengpr@gmail.com

Ana Paula Magno do Amaral

ORCID: https://orcid.org/0000-0002-1749-791X

Secretaria de Estado de Meio Ambiente e Sustentabilidade, Brasil E-mail: magno_ana@yahoo.com.br

Jefferson Salvador Lima Padilha da Silva

ORCID: https://orcid.org/0000-0001-8708-9930

Secretaria de Estado de Meio Ambiente e Sustentabilidade, Brasil

E-mail: jspadilha@agronomo.eng.br

Suelen Caroline Almeida Araujo

ORCID: https://orcid.org/0000-0002-8893-9551

Secretaria de Estado de Meio Ambiente e Sustentabilidade, Brasil

E-mail: suelen.araujo@icloud.com

Carla Vanessa Borges Castro

ORCID: https://orcid.org/0000-0002-5066-0862

Secretaria de Estado de Meio Ambiente e Sustentabilidade, Brasil

E-mail: carlavbcastro@yahoo.com.br

\begin{abstract}
Resumo
O Igarapé Ilha do Coco, está localizado na área de amortecimento da Floresta Nacional de Carajás no município de Parauapebas no Sudeste do Estado do Pará. O presente trabalho teve como objeto o crescimento populacional em um município da Amazônia que está diretamente relacionado à evolução na degradação de uma Área de Proteção Permanente-APP; essa falta de delimitação oficial para as matas ciliares são fatores que influenciam direta ou indiretamente nas ações de invasão e ocupação indevida dessas áreas legalmente protegidas, com isso houve ao longo do tempo uma perda da função sócio-ambiental do Igarapé Ilha do coco e uma continua estabilização no grau de degradação, seguido de uma recuperação significativa do ecossistema estudado.
\end{abstract}

Palavras-chave: Crescimento populacional; APP; Amazônia.

\begin{abstract}
Igarapé Ilha do Coco, is located in the buffer zone of the Carajás National Forest in the municipality of Parauapebas in the southeastern state of Pará. The present study had as its object of study how the population growth in a municipality in the Amazon is directly related to the in the degradation of a Permanent Protection Area APP; this lack of official delimitation for riparian forests, are factors that directly or indirectly influence the actions of invasion and improper occupation of these legally protected areas, with that there was, over time, a loss of the socio-environmental
\end{abstract}


function of Igarapé Ilha do coco and a stabilization in the degree of degradation continues, followed by a significant recovery of the studied ecosystem.

Keywords: Population growth; Permanent Protection Areas; Amazon.

\section{Resumen}

Igarapé Ilha do Coco, se ubica en la zona de amortiguamiento del Bosque Nacional Carajás en el municipio de Parauapebas en el sureste del estado de Pará, en la degradación de una APP Área de Protección Permanente; Esta falta de delimitación oficial para los bosques de ribera, son factores que influyen directa o indirectamente en las acciones de invasión y ocupación indebida de estas áreas legalmente protegidas, continúa la estabilización en el grado de degradación, seguida de una importante recuperación del ecosistema estudiado.

Palabras clave: Crecimiento poblacional; Áreas de Protección Permanente; Amazonas.

\section{Introdução}

As matas ciliares ou ripárianas podem ser entendidas, de maneira genérica, como as formações vegetais florestais que acompanham os veios ou cursos d'água (Melo 2004, IBGE 2012). A mata ciliar ocorre ao longo do terreno que inclui tanto a ribanceira de um rio ou córrego, de um lago ou represa, como também as superfícies de inundação chegando até as margens do corpo d'água. As matas ciliares são sistemas que funcionam como reguladores do fluxo de água, sedimentos e nutrientes entre os terrenos mais altos da bacia hidrográfica e o ecossistema aquático (SECTAM, 2006, Zamora, et al 2020).

A maioria das cidades do Brasil foram formadas ás margens de rios, apesar da legislação federal em vigor no País (Leis federais 4771/65; 9605/98; Resolução CONAMA 303/02), as matas ciliares não escaparam da destruição; sendo alvo de todo o tipo de degradação. As mesmas continuam sendo eliminadas cedendo lugar para a especulação imobiliária, para a agricultura e a pecuária e, na maioria dos casos, sendo transformadas apenas em áreas degradadas, sem qualquer tipo de produção (Oliveira et al 2011, Brito et al. 2013, Silva, 2018).

A intensa migração de pessoas ao município de Parauapebas provocou um crescimento rápido e desordenado do ambiente urbano, causando ao longo de 18 anos uma degradação considerável, principalmente das áreas de preservação permanente - APP's existentes na zona urbana, incluindo as matas ciliares. A forte especulação imobiliária nas áreas centrais da cidade tornou-se um fator de exclusão social, pressionando a procura por novas áreas para habitação, muitas vezes de forma ilegal. Os usos que outrora foram pescar, nadar, beber das águas do Ilha do Coco, estão hoje completamente perdidos dentro do perímetro que corta a zona urbana. Atualmente a Ilha do Coco é utilizado quase que exclusivamente como local de despejo de águas servidas, fato que evidencia a perda da função sócio-ambiental do igarapé (Souza et al 2020).

Com relação ao seu relevo as áreas descrevem-se como um conjunto montanhoso, cujo ponto culminante é o Pico N-5 com 814 m. O clima de Parauapebas insere-se na categoria de equatorial superúmido, tipo Am, na classificação de Köppen, no limite de transição para o Aw, caracterizando-se com temperatura média anual do ar de $26^{\circ} \mathrm{C}$, com máxima em torno de $32^{\circ} \mathrm{C}$ e mínima de $22^{\circ} \mathrm{C}$ (SETUR, 2012).

Os limites Sul e Oeste de Parauapebas são materializados, aproximadamente, pelos divisores de água das bacias do Tocantins e Xingú. Por este motivo, todos os rios do Município fazem parte da bacia do Tocantins. O município de Parauapebas é cortado de Sul a Norte por dois rios principais que nascem na Serra Arqueada, o Parauapebas e o Itacaiúnas. Segundo Fonseca e Pinheiro (2004), o Igarapé Ilha do Coco é caracterizado como um dos principais afluentes do Rio Parauapebas, com aproximadamente $25 \mathrm{~km}$ de extensão, o mesmo chega à zona urbana pelo leste da sede do município, iniciando no Bairro Caetanópolis, atravessa os bairros Da Paz, Beira Rio I e II, Rio Verde, União e Liberdade e desagua, finalmente, no Rio Parauapebas.

A Floresta Nacional de Carajás está localizada no estado do Pará, mais precisamente nos municípios de Parauapebas, Canaã dos Carajás e Água Azul do Norte. Foi criada pelo Decreto 2.486 de fevereiro de 1988. A Flona Carajás é uma unidade de conservação inserida no grupo de Unidades de Uso Sustentável de acordo com a Lei 9.985 de 18 de junho de 2000, a qual 
institui o Sistema Nacional de Unidades de Conservação - SNUC. A mesma possui uma peculiaridade que a diferencia de outras unidades de conservação existentes no Brasil, que é de abrigar a maior província mineral de ferro do mundo, embora as atividades antrópicas inseridas atualmente na Flona Carajás correspondam a menos de 2\% da área total dos 411.948,87 ha constantes no Decreto de Criação.

O Igarapé Ilha do Coco, está localizado na área de amortecimento da Flona Carajás, e suas nascentes principais originam-se na zona rural do município, onde sofrem relativa pressão com o desmatamento para introdução de novas áreas de pastagens. Sua mata ciliar na zona urbana encontra-se em elevado grau de degradação, tendo como principal causa o uso desordenado das áreas de preservação permanente, provocando sérios problemas sociais nos períodos chuvosos.

A região do município de Parauapebas, anteriormente ocupada por povos indígenas, começou a receber um crescente contingente populacional após a constatação da existência de grande reserva de minério no local e a implantação do Programa Grande Carajás - PGC e do núcleo habitacional de Parauapebas. No município explora-se principalmente minério de ferro, manganês, níquel, cobre, estanho, alumínio e ouro. Esta atividade é importante para o município, sendo a principal fonte de arrecadação, mas também tem significativa relevância para a economia regional e nacional. Sua produção é transportada numa ferrovia, que serve, em menor medida, como meio de locomoção para um número considerável de imigrantes( ICMBIO 2006).

Segundo Secretaria do meio ambiente São Paulo-SIMA (2014), os ecossistemas formados pelas matas ciliares desempenham diversas funções hidrológicas tais como:

- $\quad$ Facilitam o escoamento das águas da chuva;

- $\quad$ Diminuição do pico dos períodos de cheia;

- $\quad$ Contribuem a estabilidade das margens e barrancos de cursos d'água;

- $\quad$ Manutenção do nível do lençol freático.

Nas margens do Rio Parauapebas e demais cursos de água, a vegetação nativa apresenta adaptações à maior umidade do solo e às eventuais cheias, tornando-se distintas das demais áreas em termos fisionômicos e florísticos. Em decorrência desta pressão seletiva, a vegetação possui pequeno porte, em torno de 4-5 metros, onde predominam as Mirtáceas e Malpighiáceas, com destaque para o cipó do gênero Banisteriopsis. Nos locais atingidos por enchentes menos frequentes, a vegetação apresenta porte arbóreo e o dossel está em torno de 10m, com predomínio de ingás (Ingá edulis e Ingá sp.). Em áreas de terraços, acima do nível normal de inundação, a cobertura vegetal assemelha-se ao restante da área florestal, com destaque para a elevada frequencia de jatobás (Hymenaea courbaril). Também são encontradas algumas sapucaias (Lecythis pisonis) e castanhas (Berholletia excelsa). Muitas vezes as pastagens foram implantadas até a margem do rio, desrespeitando a norma definida pelo código florestal, que declara essas áreas como de preservação permanente.

As Matas Ciliares foram reduzidas drasticamente e, quando presentes, normalmente estão limitadas a vestígios, apesar de ser garantida pelo Código Florestal (Lei 4.771/65) como sendo áreas de preservação permanentes. Assim toda a vegetação natural (arbórea ou não) presente ao longo das margens dos rios e ao redor de nascentes e de reservatórios deve ser preservada. De acordo com o artigo $2^{\circ}$ desta Lei, a largura da faixa de mata ciliar a ser preservada está relacionada com a largura do curso d'água.

A Resolução CONAMA 303/92, que regulamenta a Lei 4.771, dispõe sobre os parâmetros, definições e limites das Áreas de Preservação Permanente (art. $2^{\circ}$ ). No Art. 3o são definidas as faixas de proteção para matas ciliares com base também na largura do curso d'água. As duas legislações acima mencionadas são reforçadas ainda pela Lei de Crimes Ambientais (Lei 9.605/98). Esta lei na sua seção II sobre crimes contra a flora estabelece que "Destruir ou danificar floresta considerada de preservação permanente, mesmo que em formação, ou utilizá-la com infringência das normas de proteção tem uma Pena de detenção de um a três anos, ou multa, ou ambas as penas cumulativamente. Aclara-se que se o crime for culposo, a pena será 
reduzida à metade $\left(\operatorname{art} 38^{\circ}\right)$.

No município de Parauapebas somente as matas ciliares do Rio Parauapebas estão protegidas pela esfera municipal. O Decreto Municipal n 110 de agosto de 2002 dispõe sobre a área de preservação ambiental permanente e veda a edificação e construção na orla do Rio Parauapebas dentro do perímetro urbano deste Município. A outra margem localizada na Floresta Nacional de Carajás tem seu potencial biótico relativamente protegido.

O Igarapé Ilha do Coco encontra-se na área de amortecimento da FLONA, porém, isso não foi o suficiente para mantê-lo preservado nem a sua mata ciliar, apesar da Legislação Federal. O Código de Posturas municipal (Lei No 4.283), revisado em 2004, incluí no seu conteúdo assuntos referentes ao meio ambiente, contudo, as matas ciliares foram mencionadas de forma muito tímida no Art. Nº101, Seção III. A Legislação Ambiental do município (Lei 4.253/02), no entanto, sequer cita o tema. Atualmente, o Poder Municipal recorre a Lei 6766/79, tratando-se da ocupação destas áreas, visto que em seu Art. 30 Parágrafo Único, Incisos I e V, são abordados de forma básica a ocupação deste tipo de área- degradação ambiental em matas ciliares.

Um ecossistema torna-se degradado quando perde sua capacidade de recuperação natural (resiliência) após distúrbios de diversa intensidade. Para a manutenção da resiliência são utilizados bancos de plântulas e de sementes no solo, chuva de sementes, etc. (Martins 2001).

Há diversos agentes responsáveis pela destruição e degradação das matas ciliares no Brasil, entre eles merecem destaque os agricultores, os garimpeiros, os mineradores de material para uso direto na construção civil, assim como os próprios atores da ocupação do espaço urbano que transformam os canais em depósitos de esgoto e rejeitos industriais (Lopes et al., 2002).

As necessidades habitacionais são expressivas em Parauapebas, podendo- se observar que os imigrantes geralmente constroem suas moradias em terrenos invadidos e sem qualquer infra- estrutura. Nestas condições as áreas de preservação permanente tais como topo de morros, nascentes, matas ciliares foram suprimidas em nome da necessidade habitacional urgente. De acordo Foladori (2001), as pessoas cuidam de sua propriedade privada ao mesmo tempo em que contaminam ou depredam e/ou poluem os espaços públicos. A natureza é um bem comum da sociedade e quem atua sobre ela deve se submeter às regulações comunitárias, sendo a depredação e/ou poluição da natureza uma questão coletiva e não individual.

\section{Metodologia}

Foi realizada a recopilação da bibliografia com base na leitura de livros, periódicos, trabalhos científicos, internet e Legislação. Foi realizada minuciosa pesquisa nos registros locais sobre o igarapé, tais como trabalhos científicos e estudos de impacto ambiental com o intuito de obter o máximo de informação, concomitantemente, foram consultados livros, periódicos e legislações pertinentes.

A pesquisa teve como base a análise visual (tonalidade, textura, forma, sombra e padrão) de fotografias coloridas, obtidas da Prefeitura Municipal - PMP e cedidas pela Companhia Vale do Rio Doce - CVRD, a primeira imagemé datada de junho de 2000, está na escala 1:1000.000 feita pela empresa Lab/GEO/IEC/SVS/MS; a segunda datada em maio de 2003, na escala 1:920.000 feita pela empresa Ortofotos; a terceira datada de agosto de 2006, na escala 1:1000.000 feita pela empresa Quickbird para CVRD e cedida a PMP; e mapas confeccionados através de levantamentos feitos pela Secretaria de Obras da PMP, ambas as fontes de informação servirão para identificar as áreas que ainda possuem uma vegetação ciliar remanescente e procurando comparar sempre os dados obtidos com a situação real encontra no campo. 
A área estudada encontra-se localizado no trecho que inicia logo após a ponte da PA 275, e vai até a ponte da Av. Liberdade. O zoneamento do trecho estudado do Igarapé Ilha do Coco foi realizado com base em quatro subáreas identificadas conforme foto 4 .

Para uma melhor descrição e análise das diferenças entre a cobertura vegetal das diversas subáreas foi definida três variáveis: ocupação do solo, vegetação e nível de regeneração natural. Esta análise multivariável permitiu criar um "índice de degradação" (Tabela 1).

Tabela 1 - Escala de identificação das variáveis analisadas nas áreas estudadas, levando-se em consideração as margens esquerda e direita.

\begin{tabular}{|c|c|c|c|c|c|}
\hline Ocupação & Valor & Vegetação & Valor & $\begin{array}{c}\text { Nível de } \\
\text { regeneração } \\
\text { natural }\end{array}$ & Valor \\
\hline $\begin{array}{c}\text { Margem não } \\
\text { ocupada }\end{array}$ & $\mathbf{0}$ & Mata nativa preservada & 1 & Regenerando & $\mathbf{0}$ \\
\hline $\begin{array}{l}\text { Margem ocupada, } \\
\text { contudo, } \\
\text { Preservando a } \\
\text { mata ciliar }\end{array}$ & 1 & $\begin{array}{c}\text { Existência de vegetação do tipomata } \\
\text { remanescente (árvores nativas ou não } \\
\text { medindo em média mais de } 3 \text { m de } \\
\text { altura) }\end{array}$ & 2 & $\begin{array}{l}\text { Não } \\
\text { regenerado }\end{array}$ & 1 \\
\hline $\begin{array}{l}\text { Margem ocupada } \\
\text { não preservandoa } \\
\text { mata ciliar }\end{array}$ & 2 & $\begin{array}{c}\text { Existência de vegetação do tipo } \\
\text { capoeira (árvores em processo de } \\
\text { crescimento > } 2 \text { m, arbustos eárvores de } \\
\text { espécies não nativas } \\
\text { e vegetação rasteira) }\end{array}$ & 3 & & \\
\hline \multirow{2}{*}{ - } & \multirow{2}{*}{ - } & $\begin{array}{l}\text { Existência de vegetação rasteira } \\
\text { (Ex.: braquiária do brejo) }\end{array}$ & 4 & & \\
\hline & & $\begin{array}{l}\text { Solo completamente desnudo } \\
\text { e/ou existência de construções }\end{array}$ & 5 & & \\
\hline
\end{tabular}

Fonte: Autores.

A análise multitemporal da degradação das áreas é realizada utilizandoa informação no período de 2000 e 2006. Após a classificação das áreas em forma individual, segundo os parâmetros acima, foi utilizada a seguinte fórmula para obter o grau de degradação:

Grau de degradação $=\quad \Sigma$ das variáveis/ Número de variáveis

Antes e após a interpretação e avaliação no laboratório, a vegetação é avaliada com visitas "in loco". Nestas oportunidades se Identificou a cobertura vegetal encontrada nas áreas de estudo, procura-se o conhecimento empírico dos moradores locais na associação dos nomes populares aos nomes científico das espécies encontradas.

Os resultados e conclusões das descrições e análises dos dados são apresentados em forma de trabalho final de conclusão de curso de especialização e futuramente em evento cientifico.

\section{Resultados e Discussão}

Em média a largura do curso d'água do Igarapé Ilha do Coco é de 10m, com base no Código Florestal (4771/65) deveriam ser preservado uma faixa de 30 metros de mata ciliar em cada uma das margens: 
Art. $2^{\circ}$ Consideram-se de preservação permanente, pelo só efeito desta Lei, as florestas e demais formas de vegetação natural situadas:

Ao longo dos rios ou de qualquer curso d'água desde o seu nível mais alto emfaixa marginal cuja largura mínima será:

1 - de 30 (trinta) metros para os cursos d'água de menos de 10 (dez)metros de largura; A rapidez com que o município de Parauapebas foi ocupado, em um intervalo de tempo de apenas três anos, criou-se dentro de um espaço, onde antes havia ainda um remanescente de mata nativa. Pode-se observar também através destas fotos que, desde o inicio da colonização local, houve pouco ou nenhum respeito a legislação federal vigente (no caso a 4771/65) no que se refere a preservação da mata ciliar do Rio Parauapebas, esta máxima pode também ser aplicada a mata do Igarapé Ilha do Coco.

Nas quatro áreas, a maior parte das espécies encontradas são: Embaúba (Cecropia sp), Inajá (Maximiliana maripa), Açaí (Euterpe oleraceae), Gameleira (), Canafistula (Cássia sp), Ingá (Inga edulis e Inga sp.), Ipê (Tebebuia sp), Azeitona (Eugenia sp.), Buriti (Mauritia flexuosa), Urucum (Bixa orelana) Mangueira (Mangifera indica), Capim braquiaria (Brachiara sp.), Taboa (Tipha dominguensis), Amendoeira (Terminalia catappa ), Coco (Cocos nucifera), Sumaúma (Ceiba penthandra), Bambus (Bambusa spp). É interessante notar que os açaizais tão comuns em áreas alagáveis no Pará, é encontrado apenas em uma das áreas de estudo (área 3), isso provavelmente em função da forte alteração causada pela ação antrópica, encontrada em todo percurso do igarapé Ilha do Coco que corta a zona urbana, esta alteração, de certa forma, desconfigura a mata ciliar com a introdução de espécies não nativas como o bambu.

Em todos os locais estudados observou-se a forte influencia antrópica, seja pela utilização na forma de pasto, ou seja, pela urbanização que se aproxima do igarapé. Locais como as áreas 3 e 4 são alvo de forte interferência humana. Esta interferência foi causadora de uma alteração considerável da mata ciliar e das áreas de influencia do igarapé (áreas de vazantes). Atualmente, a mata ali encontrada é caracterizada como um remanescente da original, em alguns pontos é apenas uma capoeira em recomposição. Estas áreas (3 e 4) são caracterizadas como sendo áreas consolidadas, estando consideravelmente urbanizadas, e estão submetidas a forte pressão imobiliária. Apesar de a sua vocação original ser residencial, e nas mesmas encontrar-se uma área residencial bem delimitada, existe uma tendência a transição do residencial para comercial com a instalação de um número considerável de empresas.

Como se pode observar no mapa planialtimétrico (Figura 1 ) as áreas objeto deste estudo, margem direita do Igarapé Ilha do Coco, situam-se entre áreas de morro e o aterro da Rodovia PA 275, fato que faz com que nas áreas 1 e 2, de menor altitude, predomine um regime de cheias e uma vegetação mais rasteira. Estas peculiaridades são um fator importante para que estas áreas não fossem afetadas pela pressão imobiliária. 
Figura 1 - Mapa em curva de nível da área objeto do estudo - Mapa cedido pela Secretaria deObras - SEMOB/PMP.

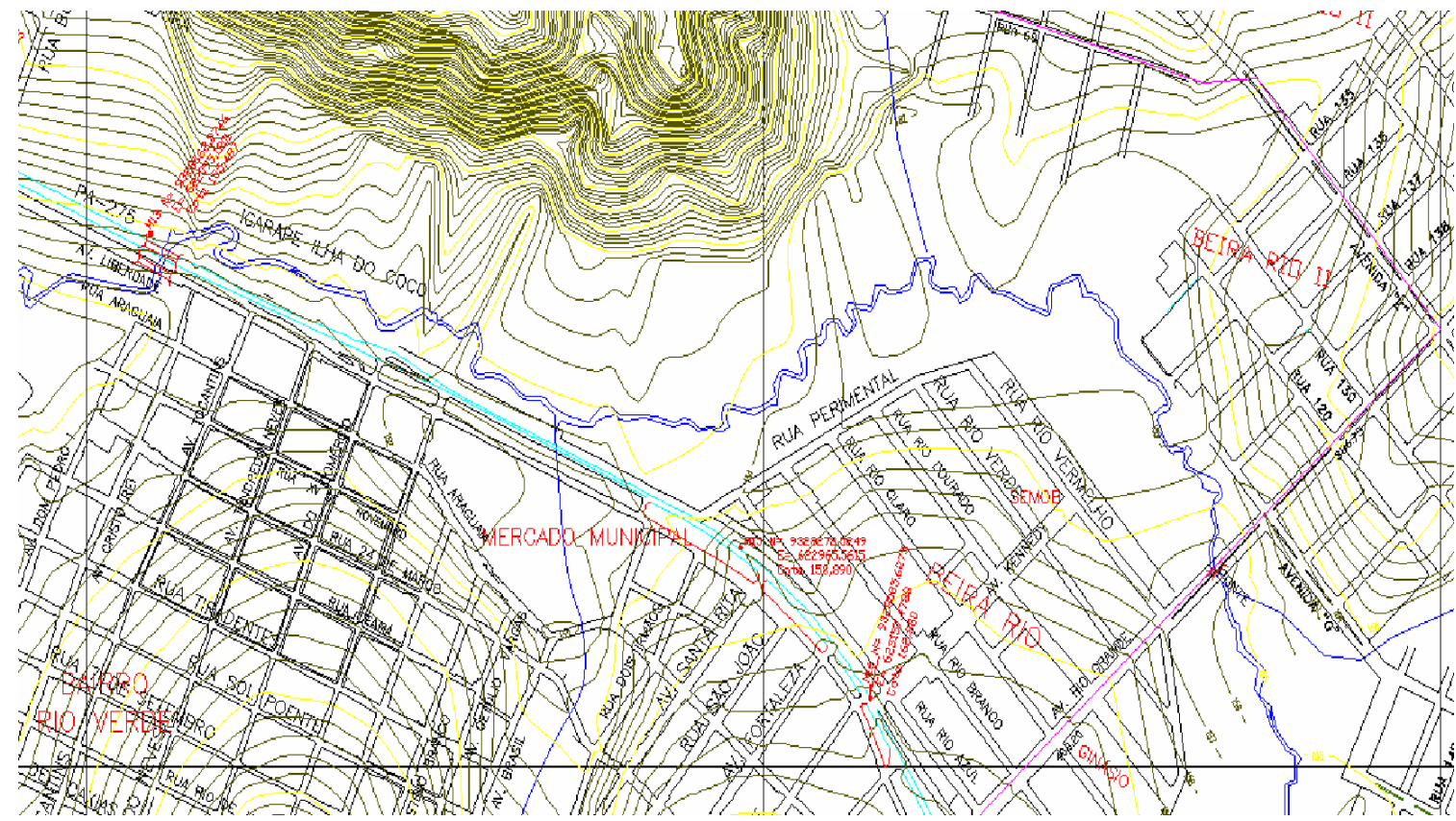

Fonte: Nascimento (2007).

Comparando as fotografias dos anos 2000 e 2006 (Fotos 1 e 2), visualiza-se setores com evidências de recuperação da mata ciliar, observa-se ainda, setores próximos ao bairro Beira Rio II (indicado com setas). Nestas áreas foi possível observar ainda, uma mata de recomposição, ou seja, árvores de pequeno porte do extrato primário, normalmente acompanhadas ainda pelo capim braquiaria do brejo e/ou taboa, a presença de embaúba, espécie indicadora de áreas em regeneração, é significante em todas as áreas estudadas.

Foto 1 - Área objeto do estudo, ano de 2000.

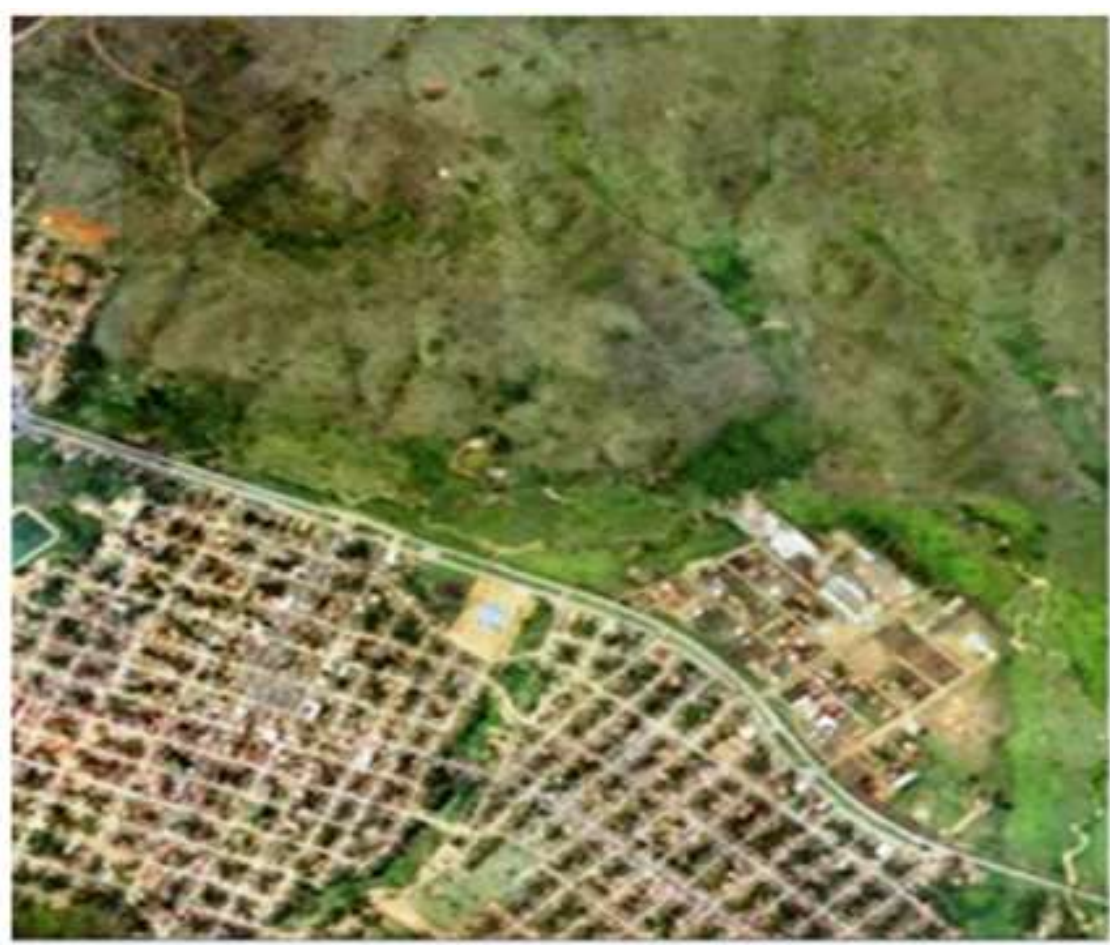

Fonte: Autores. 
Foto 2 - Área objeto do estudo, ano de 2006.

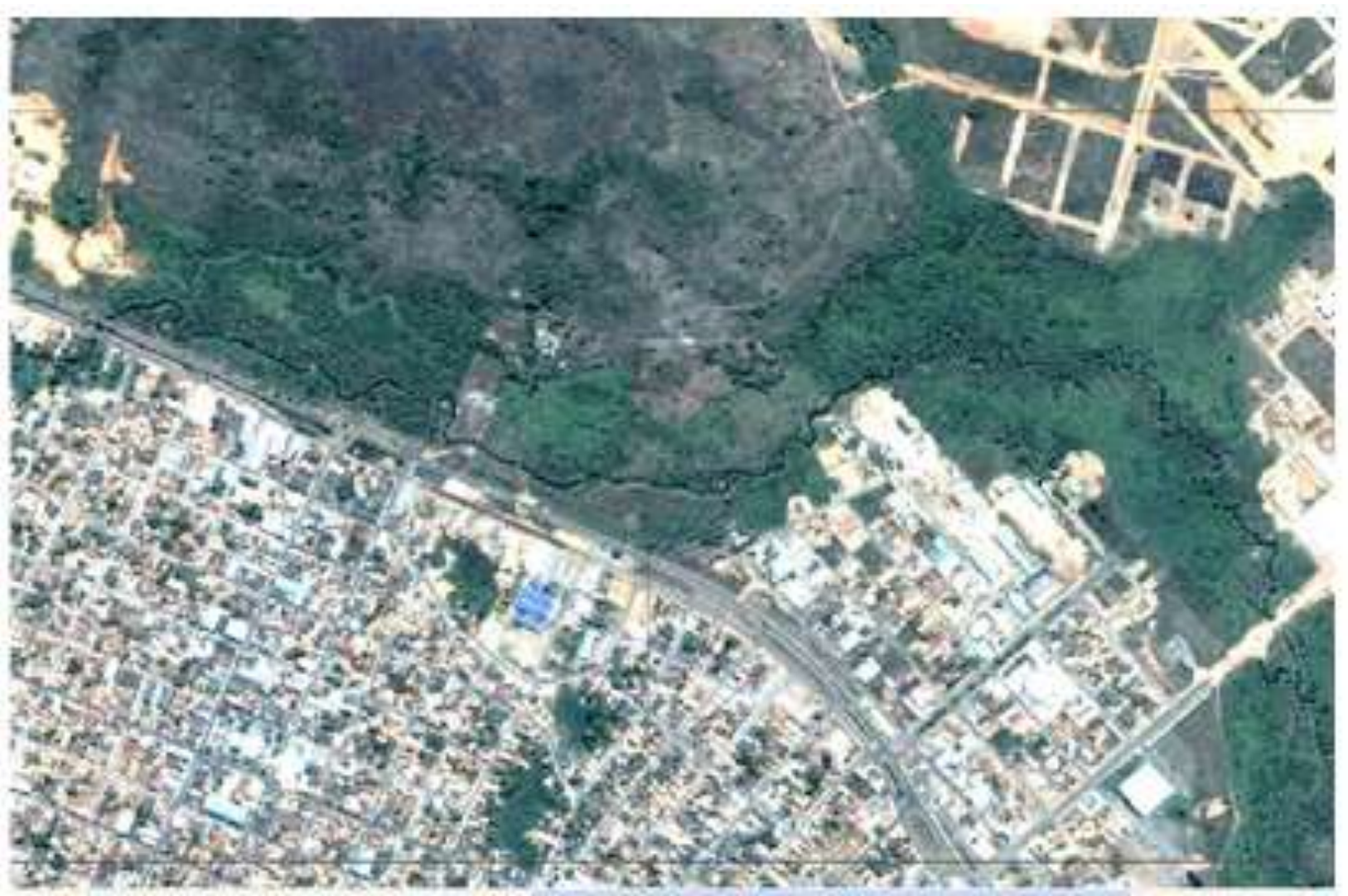

Fonte: Autores.

Observa-se, entretanto, que o ecossistema estudado foi alvo de forte degradação nos primórdios da colonização do município, e locais onde outrora predominava a mata ciliar cedeu lugar ao pasto. Contudo, a sua capacidade de resiliência não foi totalmente perdida; a vegetação rasteira que predominava na fotografia do ano 2000, cede lugar vagarosamente a uma capoeira e em alguns locais, a mata de regeneração natural. Esta recuperação em muitos casos se dá pela presença de um banco de sementes no próprio solo, e/ou o trabalho incessante dos animais (mamíferos de pequeno porte, aves etc.). Estudos mostram que o enriquecimento de áreas é a alternativa técnica mais segura, mesmo que mais custoso que os métodos naturais que são mais baratos porém, mais demorados. Uma mata ciliar reflorestada certamente chegará ao seu clímax mais rapidamente do que uma área de mata ciliar de regeneração natural. De acordo com Melo (2004), em função da sua importância são crescentes os esforços para restauração de matas ciliares. Kageyama e Gandara (2000) creditam este fato à conscientização da sociedade, as exigências legais e ao aumento das iniciativas de restauração.

Para melhor análise da área, a mesma foi subdividida em 4 áreas (Foto 3). 
Foto 3 - Subáreas objeto do estudo.

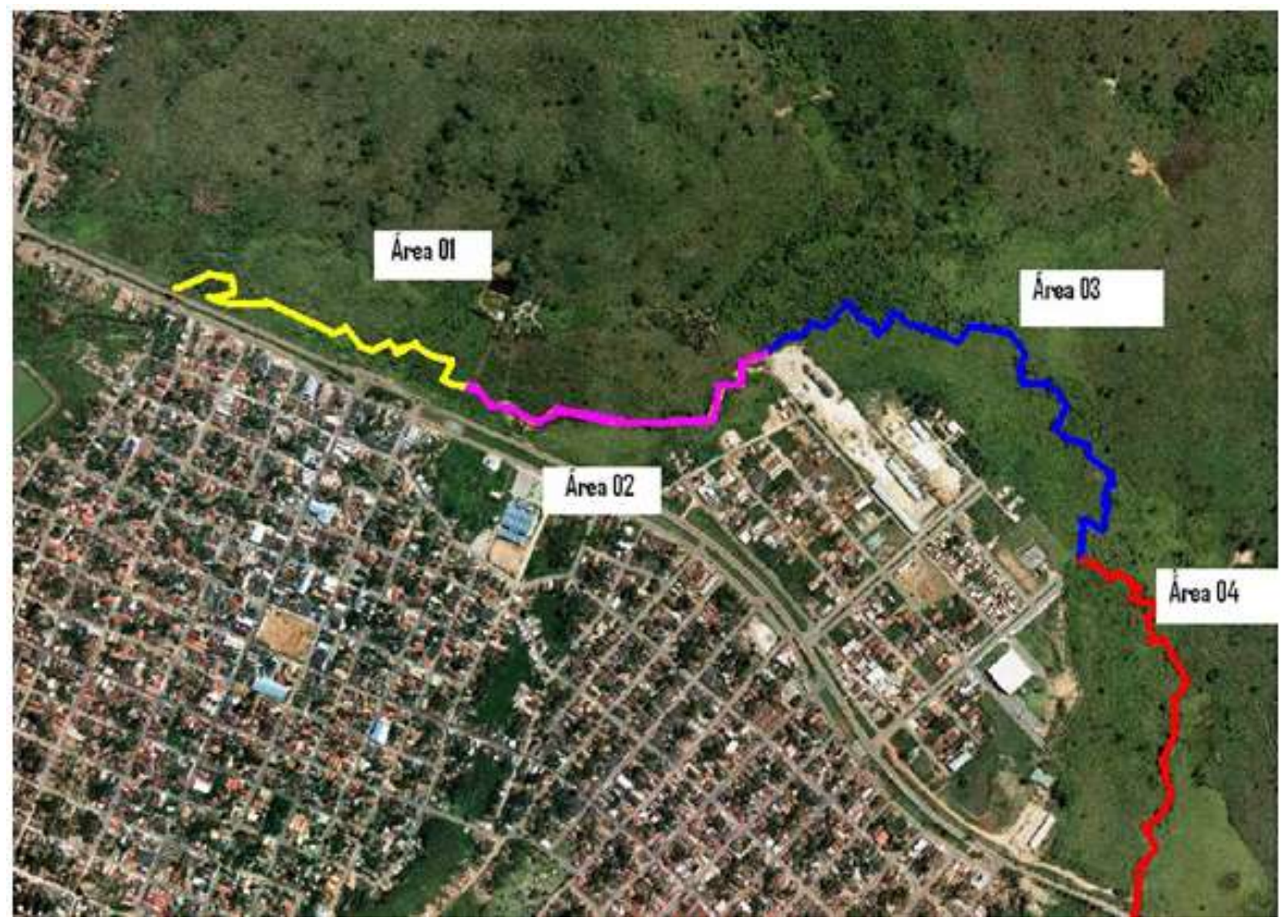

Fonte: Autores.

Com relação à análise das fotografias aéreas, podemos observar as seguintes características, conforme o Quadro 1 .

Quadro 1 - Avaliação do grau de degradação da mata ciliar do Igarapé Ilha do Coco, nos anos de 2000, 2003 e 2006, conforme fotografias aéreas, nas escalas: 1:1.000.000, 1:960.000 e 1:1.000.000 respectivamente, cedidas pela CVRD a Prefeitura Municipal de Parauapebas.

\begin{tabular}{|c|c|c|c|c|c|c|c|c|c|c|c|c|c|c|c|c|c|c|c|}
\hline \multirow{3}{*}{ 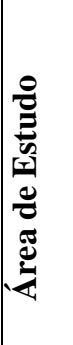 } & \multicolumn{19}{|c|}{ ANO DA FOTOGRAFIA } \\
\hline & \multicolumn{6}{|c|}{2000} & \multicolumn{7}{|c|}{2003} & \multicolumn{6}{|c|}{2006} \\
\hline & 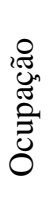 & 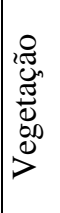 & $\begin{array}{l}\frac{8}{8} \\
\frac{0}{2} \\
i\end{array}$ & 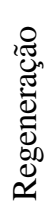 & 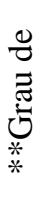 & 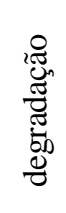 & 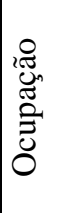 & 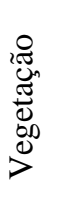 & $\begin{array}{l}\frac{0}{0} \\
0 \\
z \\
z\end{array}$ & 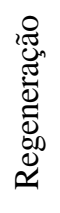 & 胥 & 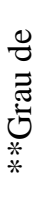 & 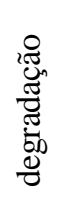 & 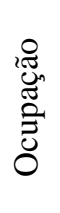 & 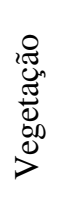 & 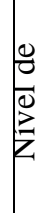 & 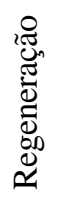 & 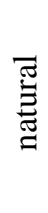 & 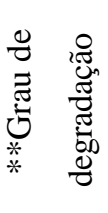 \\
\hline 1 & 0 & 3 & 1 & & & 1,33 & 0 & 3 & & 0 & & & 1,00 & 1 & 3 & & 0 & & 1,33 \\
\hline 2 & 1 & 4 & 1 & & & 2,00 & 2 & 3 & & 1 & & & 2,00 & 1 & 4 & & 1 & & 2,00 \\
\hline 3 & 0 & 4 & 1 & & & 1,66 & 1 & 3 & & 0 & & & 1,33 & 0 & 3 & & 0 & & 1,00 \\
\hline 4 & 0 & 4 & 1 & & & 1,66 & 1 & 3 & & 1 & & & 1,66 & 0 & 3 & & 0 & & 1,00 \\
\hline
\end{tabular}

** O Grau de Degradação é dado pela seguinte fórmula: GD = $\Sigma$ variáveis/Número de variáveis. Fonte: Autores.

Com base na tabela acima e a análise das fotografias aéreas (Fotos 1, 2 e 3), observam-se locais pontuais onde se pode 
encontrar uma vegetação de porte arbóreo em toda área em estudo. Podemos visualizar uma interferência considerável do homem ao longo do curso do Igarapé. Observamos a existência apenas de uma vegetação rasteira (pasto), caracterizando assim uma degradação bem considerável da mata nativa, quase inexistindo árvores de porte elevado na margem esquerda do Igarapé para todas as áreas na fotografia do ano 2000. Contudo, na fotografia datada do ano de 2003 a situação se inverte na margem direita, e é visível uma sutil recuperação da mata, pode-se observar o crescimento de uma vegetação de porte mais elevado, tendendo a formação de uma capoeira, que futuramente irá gerar uma mata secundária. Fato que reduz o grau de degradação para o local. Observamos na fotografia datada do ano 2006 que, apesar da mata secundária estar em formação, é possível visualizar que a mesma sofre pressão antrópica, ou seja, a existência de empreendimentos e chácaras localizadas em áreas de influência do Igarapé (vazantes) colocam em risco a integridade da mata ciliar definida em Lei (Art. $2^{\circ}$ alíneas a e b da Lei 4771/65):

Pode-se observar na fotografia do ano de 2000 que a área 1 apresenta, predominante, uma cobertura vegetal rasteira (pasto) é visível ainda, uma faixa de vegetação de porte mais elevado na margem esquerda na referida área. Esta característica permanece até o ano de 2003. Contudo, há uma regeneração natural do extrato arbóreo de ambas as margens; assim sendo, o grau de degradação se reduz entre os anos de 2000 a 2003, sendo o resultado mais significativo para a margem direita, esta condição se inverte na fotografia do ano de 2006.

Na fotografia do ano 2000, a área 2 encontrava-se com um forte grau de degradação. Esta situação se manteve estável nas três fotografias analisadas. Não houve uma progressão no desmatamento, no entanto, não houve também uma regeneração natural. Este trecho se manteve com uma vegetação predominantemente rasteira.

A área 3 manteve uma tendência à regeneração natural, apesar da criação no entorno desta área do bairro Beira Rio II (foto 3, ano de 2006). As características da vegetação nesta área são bem típicas de áreas alagadas nos trechos iniciais pode-se observar uma vegetação rasteira onde provavelmente predominava a braquiaria do brejo e/ou a taboa. No intervalo de seis anos, entre as fotografias, ocorreu uma recuperação natural, com a formação de uma capoeira. Em alguns locais, na área 3, a urbanização chega bem próxima a margem do Igarapé, este fator indica a possibilidade de ocupações indevidas destas margens, que são áreas protegidas por lei.

A área 4 teve a princípio um grau de degradação relativamente alto $(1,66)$. No ano 2003, este grau se manteve havendo apenas uma discreta recuperação da vegetação arbórea. Em 2006 a regeneração natural foi mais intensa. Em grande parte desta área predomina o capim braquiária e a taboa, provavelmente pelas características destes setores como locais que ficam alagados durante os períodos de cheias (vazante) do igarapé. 
Gráfico 1 - Grau de degradação das áreas em estudo nos anos 2000, 2003 e 2006.

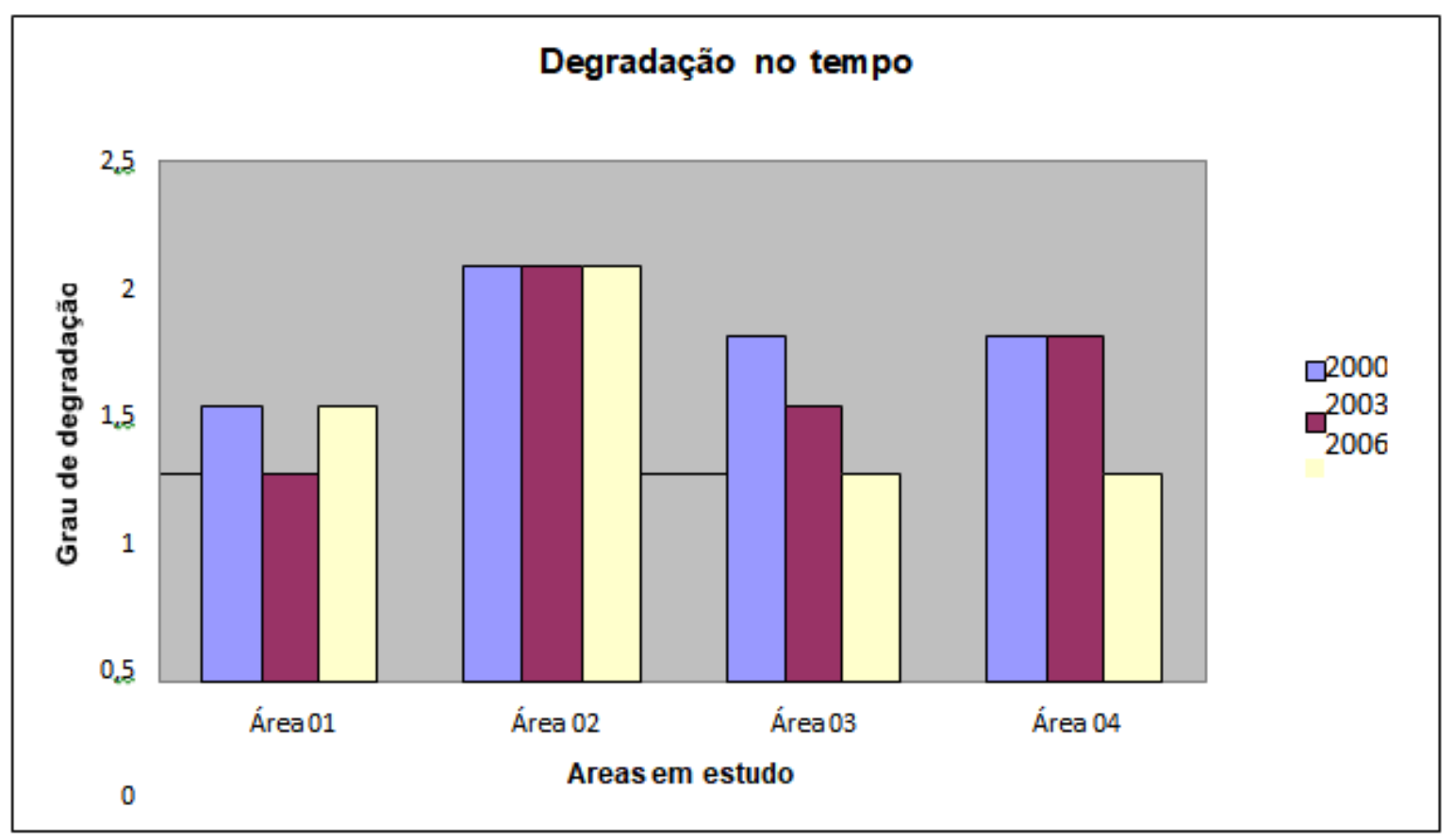

Fonte: Autores.

Baseado no gráfico acima podemos afirmar que a recuperação das áreas 3 e 4 pode ter ocorrido em função que no ano 2000, a vegetação era predominantemente pasto, o qual foi aparentemente abandonado. Desta forma teriam cessado as queimadas permitindo criar condições para a regeneração da vegetação de porte mais elevado (ex. embaúba).

Observou-se também que o estabelecimento de um novo bairro na margem direita do Igarapé (Bairro Beira Rio II) pouco interferiu na regeneração da mata. É cauteloso, no entanto, mencionar que deve haver um controle rígido da largura de margem e áreas de vazante do Igarapé quando se tratar de áreas edificáveis para este bairro, principalmente no que se refere ao uso do solo. É necessário também, uma legislação municipal, que localize e determine o uso para estas áreas, ou seja, fatores que dificultem a ocupação indevida e incentivem a recuperação destes espaços verdes.

Por não existir ainda uma legislação para uso e ocupação do solo. Atualmente, tanto o Código de Posturas quanto a Lei 6766/79 são muito utilizadas para manter o ordenamento da ocupação no município.

\section{Considerações Finais}

O crescimento populacional do município de Parauapebas está diretamente relacionado à evolução na degradação da mata ciliar do Igarapé Ilha do Coco;

São vários os fatores que movem a indústria da invasão, como por exemplo, a intensa migração, o baixo poder aquisitivo dos mesmos, além da expectativa de levar vantagem de alguma forma com a desapropriação e/ou expropriação destas áreas, a falta de uma legislação municipal para o uso do solo que delimite as ações de invasão e ocupação indevida das APP's;

Houve ao longo do tempo uma perda da função sócio-ambiental do Igarapé Ilha do Coco, bem como perda de área de lazer para população de baixa renda;

No geral houve uma estagnação e/ou uma regeneração da mata ciliar igarapé Ilha do Coco nas áreas estudadas; 
Apesar da legislação vigente teoricamente proteger este tipo de ecossistema, observou-se que a degradação era bem mais acentuada, ao longo destes seis anos, no entanto, houve uma contenção e muitos casos uma recuperação da mata, fato ocorrido possivelmente devido a um maior ordenamento e cuidado do poder publico, e da população para com a mata ciliar.

\section{Referências}

Queiroz, A. R. (2009). Desafios de implantação de infraestrutura de saneamento e ocupação do solo urbano na cidade de Manaus, Amazonas. Dissertação apresentada ao Programa de Pós-Graduação em Ciências do Ambiente e Sustentabilidade na Amazônia - PPG/CASA, da Universidade Federal do Amazonas - UFAM.

Brandt. (2000). Meio Ambiente. Mineração Serra do Sossego S. A. - Estudo de Impacto Ambiental / EIA.

Brito, R. M., Silva, M. C. da, \& Araujo, K. D. (2013). Degradação das matas ciliares em Aragominas - TO. Geoambiente On-Line, (8), 01-13. https://doi.org/10.5216/rev. geoambie.v0i8.25929

Foladori, G. (2001). Limites do desenvolvimento Sustentável. Marise Manoel. Editora Imprensa Oficial, 224p.

Fonseca, A. B., Pinheiro, R. P. (2004). Preservação e sustentabilidade do ecossistema do Igarapé Ilha do Coco - Trecho Bairro da Paz. Trabalho Acadêmico de Conclusão de Curso. 41p. Universidade Federal de Educação Tecnológica do Para - CEFET/PA.

Furtado, R. G., Nascimento, M. Z. B., Caetano, S. (2005). Projeto de recuperação e proteção das nascentes e margens do Igarapé Ilha do Coco. Prefeitura Municipal de Parauapebas. Secretaria Municipal de Meio Ambiente / Captação de Recursos. 58p.

Silva, G. M., Rocha, M. Y. T., Albuquerque, A. R. C. (2018). Diagnóstico socioambiental da comunidade do crespo, Manaus/Amazonas. Geoambiente online. $\mathrm{n}$ 32. https://doi.org/10.5216/revgeoamb.v0i32.48606

Secretaria do meio ambiente São Paulo. (2014). Matas ciliares. Cadernos de Educação Ambiental. (2a ed.), 82 p. https://smastr16.blob.core.windows.net/cea/2014/11/7-matas-ciliares.pdf

Instituto Brasileiro de Geografia e Estatística. (2012). Manual técnico da vegetação brasileira.2 ${ }^{\mathrm{a}}$ Edição, Manuais Técnicos em Geociências número 1.

Instituto Chico Mendes de Conservação da Biodiversidade. (2006). Plano de manejo da floresta nacional de carajás. 202p. https://www.icmbio.gov.br/portal/images/stories/biodiversidade/UC-RPPN/DCOM_ICMBio_plano_de_manejo_Flona_Carajas_volume_I.pdf

Kageyama P. Y., Gandara, F. B. (2000). Recuperação de áreas ciliares. In: Melo, A. C. G. (2004). Reflorestamentos e restauração de matas ciliares: análise estrutural e método de monitoramento no médio vale do Paranapanema (SP). Dissertação de Mestrado. Universidade de São Paulo. São Carlos. 151 p.

Lara, P.T., Peters, E. L. (2001). Legislação Ambiental Federal. Ed. Juruá. 362 p.

Lopes, I. G. V. Gestão Ambiental no Brasil. Experiência e sucesso. (4a ed.). Fundação Getúlio Vargas. 408 p.

Lorenzi, H. (2002). Arvores brasileiras, V.1. Plantarum. (4a ed.).

Martins, s. V. (2001). Recuperação de matas ciliares. Editora Aprenda Fácil.

Melo, A. C. G. (2004). Reflorestamentos e restauração de matas ciliares: análise estrutural e método de monitoramento no médio vale do Paranapanema (SP). Dissertação de Mestrado. Universidade de São Paulo. 151 p. https://www.teses.usp.br/teses/disponiveis/18/18139/tde-29092005-150857/pt-br.php

Nascimento, M. Z. B. (2007). Identificação e avaliação de remanescentes de mata Ciliar do igarapé Ilha do Coco presentes em Área Urbana do município de Parauapebas/PA. Curso de especialização em Planejamento urbano e gestão Local NAEA/UFPA.

Oliveira, L. C., Pereira, R., Vieira, J. R. G. (2011). Análise da degradação ambiental da mata ciliar em um trecho do rio Maxaranguape - RN: uma contribuição à gestão dos recursos Hídricos do Rio grande do norte - Brasil. Holos, 5, 49-66. https://www.redalyc.org/pdf/4815/481549218006.pdf.

Secretaria de ciência, tecnologia e meio ambiente- Belém. (2006). Matas ciliares: preservá-las é nosso dever. 24p. https://www.semas.pa.gov.br/wpcontent/uploads/2018/05/Cartilha_Matas_Ciliares.pdf

Santo, S. M. E. (2004). Vegetação Ripária e Manguesais. Um paradoxo entre diferenças e similaridades. Dissertação de Mestrado. UFSC. https://www.academia.edu/1888006/vegeta\%c3\%87\%c3\%83o_rip\%c3\%81ria_e_manguezais_um_paradoxo_entre_diferen\%c3\%87as_e_similaridades

Secretaria de Turismo do Pará. (2012). Inventário da oferta turística de Parauapebas-PA. http://www.setur.pa.gov.br/sites/default/files/pdf/inventario_parauapebas_0.pdf.

Silva, E. C. (2018). Percepção ambiental sobre a degradação da mata ciliar em torno das margens da comunidade de rio Alto Ajuaí (Abaetetuba-Pa). Trabalho de Conclusão de Curso. Universidade Federal do Pará, Abaetetuba. https://bdm.ufpa.br/jspui/handle/prefix/2413.

Souza, L. C., Santos, F. L., Galdino, V. S., Dias, G. F. M., Luz, D. D., Miranda, S. B. A. (2020). Análise socioambiental dos moradores da área de preservação permanente urbana do igarapé Ilha do Coco em Parauapebas - Pará. Research, Society and Development, 9(11), e54091110336. 10.33448/rsd-v9i11.10336. https://rsdjournal.org/index.php/rsd/article/view/10336.

Zamora, V. R. O., Cruz, A. F. S., Andrade, A. R. S., Silva, E. G., Andrade, E. K. P., Silva, J. D. S., Silva, E. T. (2020). Classificação supervisionada das áreas de influência da mata ciliar nas barragens Goitá e Tapacurá mediante Spring. Research, Society and Development, 9(11), e4829119947. 10.33448/rsdv9i11.9947. https://rsdjournal.org/index.php/rsd/article/view/9947. 